\title{
The safety of commonly used vitamins and minerals
}

\section{SUMMARY}

Dietary supplements are the most common type of complementary medicine in Australia, reportedly used by $47 \%$ of the population. Vitamins and minerals are particularly popular.

Like all medicines, supplements can cause potential harms such as adverse reactions, drug interactions, monetary cost, delay of more effective therapy, false hope, and increased medication burden.

Although most vitamins and minerals are available for open sale, many are subject to legal restrictions as scheduled medicines, depending on the dose.

Consumers are at risk of overdose when the same ingredient is present in multiple products.

Health professionals can assist consumers by discussing the potential benefits and harms of vitamins and minerals and assisting them to find authoritative information.

Adverse events with vitamins and minerals should be reported to the Therapeutic Goods Administration.

\section{Introduction}

Dietary supplements are natural health products used to supplement the diet, such as vitamins, minerals, amino acids, enzymes, plant extracts, algae and macroscopic fungi.' Although these products are more commonly referred to as complementary medicines in Australia, particularly for regulatory purposes by the Therapeutic Goods Administration (TGA), the term dietary supplement is frequently used by consumers whose intention is to augment their diet rather than treat disease.

Dietary supplements dominate the complementary medicines industry in Australia. Sales reached AU $\$ 5.6$ billion in 2019 after having more than doubled over the preceding 10 years. ${ }^{2}$ Complementary medicines are in widespread use in Australia, with a recent national survey showing $63 \%$ of people use them regularly. Dietary supplements containing vitamins and minerals were the most popular type of complementary medicine and were reportedly used by $47 \%$ of respondents. ${ }^{3}$

\section{Potential harms of vitamins and minerals}

One reason for the persistent popularity of vitamins and minerals is the perception that they are harmless. There are many potential harms (see Box 1 for potential adverse effects of commonly used vitamins and minerals) but, unlike conventional medicines, manufacturers of vitamins and minerals are not required to submit extensive documentation about safety or effectiveness of their products in order to be included in the Australian Register of Therapeutic Goods.

It is wise to remember that there are several different types of harm that can occur with any medicine other than just adverse drug reactions. See Box 2 for the six potential harms which may be a helpful guide to risk assessment. ${ }^{4}$

Marketing of vitamins and minerals is generally based on their claimed benefits with little, if any, mention of their potential harms. Consumer information leaflets are not provided, and few dietary supplements carry warnings of potential adverse effects on their packaging. Nonetheless, there are well-recognised harms from the ingredients of dietary supplements, especially when taken in high doses. For example, higher dose products of vitamin A and selenium are regulated as Schedule 2, 3 and 4 medicines because of their documented toxicity.

Vitamins and minerals are generally used safely when prescribed in medical settings for the treatment or prevention of deficiency states and other appropriate conditions. For example, vitamin $\mathrm{B}_{3}$ is used for hyperlipidaemias and folic acid is used in pregnancy to prevent birth defects (e.g. anencephaly, spina bifida). The key to the safety of vitamins and minerals is the prescribed dose, which is usually derived from research demonstrating that the benefits outweigh the harms. This is often not the case when consumers are self-medicating with products purchased on the open market, as consideration is rarely given to the

\section{Geraldine Moses AM} Consultant clinical pharmacist, Mater Health Services

Adjunct associate professor, School of Pharmacy, University of Queensland Brisbane

\section{Keywords}

adverse effects, complementary medicines, dietary supplements, minerals, safety, vitamins

Aust Prescr 2021;44:119-23 https://doi.org/10.18773/ austprescr.2021.029 


\section{Box 1 Potential adverse effects of commonly used vitamins and minerals}

\section{Vitamin A/retinol}

Acute toxicity associated with ingestion $>300,000$ IU. Chronic toxicity (hypervitaminosis) associated with doses $>10,000 \mathrm{IU} /$ day. Symptoms of chronic hypervitaminosis A include skin desquamation, liver impairment, loss of vision and severe intracranial hypertension.

\section{Vitamin $B_{3} /$ niacin/nicotinic acid}

Moderate to high doses of vitamin $\mathrm{B}_{3}$ are commonly associated with peripheral vasodilation causing skin flushing, burning sensation, pruritus and hypotension. Vasodilation may also occur in the eye resulting in reversible toxic cystoid macular oedema.

\section{Vitamin $\mathrm{B}_{6}$ /pyridoxine}

Doses $\geq 200 \mathrm{mg} /$ day of vitamin $B_{6}$ have been associated with severe sensory peripheral neuropathies. Risk often arises from multiple products being taken all containing pyridoxine.

\section{Vitamin C/ascorbic acid}

Associated with precipitation of cysteine, urate or oxalate kidney stones, especially in people with a predisposition for kidney stones. Vitamin C may reduce effectiveness of antineoplastic drugs such as vincristine, doxorubicin, methotrexate, cisplatin and imatinib.

\section{Vitamin D/colecalciferol}

Very high doses may cause hypercalcaemia, with symptoms from thirst and polyuria to seizures, coma and death. High intermittent doses of vitamin D have been associated with increased risk of falls and fracture in the elderly.
Vitamin E/alpha-tocopherol

Antiplatelet effect and increased risk of haemorrhagic stroke reported.

\section{Calcium}

Carbonate salt can cause gastric reflux and constipation. High-dose calcium may induce vascular and soft tissue calcification, hypercalciuria, kidney stones and secondary hypoparathyroidism. Interferes with absorption of magnesium, iron and zinc if taken simultaneously, and can reduce absorption of many other drugs e.g. levothyroxine, tetracyclines.

\section{Magnesium}

High doses often result in diarrhoea, nausea and abdominal cramping due to the osmotic effect. Like other divalent cations, magnesium may chelate and reduce absorption of other minerals or medicines such as tetracyclines.

\section{Zinc}

Often associated with altered or impaired taste and smell. Intranasal zinc can cause anosmia. Doses $\geq 80 \mathrm{mg} /$ day in clinical trials were associated with adverse prostate effects.

\section{Selenium}

Associated with acute and chronic toxicity. Signs of chronic high-dose 'selenosis' are hair and nail loss or brittleness, lesions of the skin and nervous system, nausea, diarrhoea, skin rashes, mottled teeth, fatigue and mood irritability.

\section{Box 2 Six potential harms of a supplement or medicine}

\section{Adverse effects}

Adverse effects should be considered from short- or long-term use, high or low dose, risk during pregnancy or breastfeeding, influence on disease, fertility or malignancy.

\section{Drug interactions}

Drug-drug or drug-disease interactions, dynamic or kinetic.

Enzyme and transporter interactions, all of which can make other drugs more toxic or less effective.

\section{Cost}

The cost of dietary supplements can be harmful due to its impact on finances and the ability to afford treatment or other essential items.

\section{Delay of more effective therapy}

Time spent taking ineffective products may delay more effective interventions, waste valuable time and allow disease progression.

\section{False hope or fraud}

Falling for fraudulent claims offering false hope can be demoralising and depressing, which for some can make the difference between continuing to manage a health condition and giving up hope.

\section{Medication burden}

As the number of medicines and supplements increases, so too does the burden of polypharmacy which increases the risk of medication error, interactions and adverse events.

Adapted from reference 4 effective or safe dose. Indeed, overdose of ingredients from multiple products, such as pyridoxine or vitamin $A$, is a much-neglected risk.

For consumers to make balanced and informed decisions about using dietary supplements, details regarding both their benefits and harms should be evidence-based and readily available. Such information can be found, especially on the internet, but consumers have to be motivated to look, know where to look, and know how to critique the information. Health professionals can assist consumers by openly discussing the risks and benefits of dietary supplements, explain why dose is important, and direct them where to go for higher quality information beyond advertising and the manufacturer's label. See Box 3 for links to information resources freely available to both consumers and health professionals regarding dietary supplements and complementary medicines.

When taking a comprehensive history, health professionals should include dietary supplements, detailing the brand, its ingredients and the dose taken in order to assess both the potential benefits and risks, and the potential for cumulative overdose from multiple products. As with all medicines, adverse events associated with dietary supplements should be reported to the TGA ensuring brand names are specified so all ingredients can be identified. 


\section{Box 3 Freely available resources regarding dietary supplements and complementary medicines}

\author{
About Herbs - Memorial Sloane Kettering Cancer \\ Care Centre \\ http://www.mskcc.org/cancer-care/diagnosis- \\ treatment/symptom-management/integrative- \\ medicine/herbs/search

\section{Drugs.com} \\ www.drugs.com
}

National Institutes of Health, Office of Dietary Supplements

https://ods.od.nih.gov/Healthlnformation/ makingdecisions.sec.aspx

National Institutes of Health, National Center for Complementary and Integrative Health www.nccih.nih.gov

\section{Vitamin A}

Vitamin A, also known as retinol, is associated with acute and chronic toxicity. Acute toxicity is mostly caused by accidental ingestion of 300,000 IU or more. ${ }^{5}$ Signs and symptoms include headache, blurred vision, dizziness, nausea, vomiting and reduced motor coordination secondary to intracranial hypertension. ${ }^{6}$

Vitamin A toxicity can occur with regular ingestion of more than 100,000 IU daily, which may be contributed to by synthetic retinoids. Symptoms of chronic hypervitaminosis A include skin desquamation, liver impairment, loss of vision and severe intracranial hypertension. ${ }^{6}$

Vitamin A taken by pregnant women is associated with birth defects. Ingestion of high-dose vitamin A (>15,000 IU/day from combined sources of food and supplements or $>10,000 \mathrm{IU} /$ day from supplements only) has been associated with an increased incidence of craniofacial malformations as well as central nervous system, heart and limb abnormalities. ${ }^{7}$

\section{Vitamin $\mathbf{B}_{3}$}

Moderate to high doses of vitamin $\mathrm{B}_{3}$ (niacin/ nicotinic acid) (500 mg/day or more) are commonly associated with peripheral vasodilatation causing skin flushing, burning sensation, generalised pruritus and hypotension, lasting for 20-30 minutes and declining in severity and frequency with time. ${ }^{8}$ Niacin-induced vasodilatation also occurs in the eyes. This can result in reversible toxic cystoid macular oedema in $0.67 \%$ of patients taking doses of niacin 3-4.5 g daily. ${ }^{9}$ Doses of
$3 \mathrm{~g}$ or more of niacin per day have caused blurred vision, eyelid oedema, toxic amblyopia, proptosis, loss of eyelashes or eyebrows and superficial punctate keratitis. ${ }^{10}$

\section{Vitamin $\mathbf{B}_{6}$}

Vitamin $\mathrm{B}_{6}$ (pyridoxine) has been associated with severe sensory peripheral neuropathies most frequently in doses over 200 mg/day. ${ }^{6}$ Because of this potential neurotoxicity, products containing pyridoxine with a daily dose more than $200 \mathrm{mg} /$ day are Schedule 4 prescription-only medicines in Australia and overseas."

\section{Vitamin C}

Urine acidification from supplemental vitamin C (ascorbic acid) in doses as low as 250 mg/day has been associated with precipitation of cysteine, urate or oxalate kidney stones, especially in men and people with a predisposition for kidney stones. ${ }^{6,12-14}$ Vitamin C also has many well-known pharmacodynamic drug interactions. One of the more serious interactions is that it may reduce the effectiveness of antineoplastic drugs such as vincristine, doxorubicin, methotrexate, cisplatin and imatinib. ${ }^{15}$

\section{Vitamin D}

Vitamin D (colecalciferol) in doses of 1000-2000 IU/day is well tolerated. However, there are increasing reports of toxicity which appear to relate to manufacturing errors, prescribing errors and the increasing use of high-dose supplements. Toxicity is mediated through hypercalcaemia, with symptoms ranging from thirst and polyuria to seizures, coma and death. ${ }^{16}$ High-dose vitamin $D$ in the range of 300,000-500,000 IU administered as an annual intramuscular injection for osteoporosis has been associated with increased risk of fracture. 17,18 Doses of 4000-10,000 IU/day have been associated with diminished bone density. ${ }^{19}$

\section{Vitamin E}

Vitamin $\mathrm{E}$ has been associated with an antiplatelet effect and two clinical trials have found an increased risk of haemorrhagic stroke in people taking alphatocopherol. ${ }^{20}$ Two meta-analyses of randomised trials have also raised questions about the safety of highdose vitamin $\mathrm{E}$ in daily doses of $400 \mathrm{IU}$ or more for over one year, which have linked supplementation with small but statistically significant increases in allcause mortality. ${ }^{6,21}$

\section{Calcium}

Calcium supplementation, especially in the carbonate salt, can cause gastric reflux and constipation.

High-dose calcium may induce vascular and soft 
tissue calcification, hypercalciuria, kidney stones and secondary hypoparathryoidism. ${ }^{22}$ Calcium also interferes with the absorption of magnesium, iron and zinc if taken simultaneously. ${ }^{23}$

\section{Magnesium}

Magnesium in high doses from dietary supplements or medicines often results in diarrhoea, nausea and abdominal cramping due to the osmotic effect of unabsorbed salts in the intestine. ${ }^{24}$ The salts most likely to cause diarrhoea are magnesium carbonate, chloride, gluconate and oxide. ${ }^{6}$ Symptoms of hypermagnesaemia usually develop when serum concentrations exceed $1.74-2.61 \mathrm{mmol} / \mathrm{L}$ and include hypotension, nausea, vomiting, facial flushing, urine retention, ileus, depression and lethargy. This may progress to muscle weakness, difficulty breathing, extreme hypotension, irregular heartbeat and cardiac arrest. ${ }^{25}$

\section{Zinc}

Zinc, even in small doses, is associated with adverse effects on taste and smell. Anosmia is associated with intranasal use. ${ }^{6}$ Acute high-dose zinc ( $>40 \mathrm{mg} /$ day) can cause nausea, vomiting, abdominal cramps, diarrhoea and headaches. ${ }^{26}$ It is well established that long-term high-dose zinc can induce copper deficiency. ${ }^{6}$ In the Age-Related Eye Disease study (AREDS), $80 \mathrm{mg} /$ day of zinc oxide for an average of 6.3 years was associated with a significant increase in hospitalisations for genitourinary causes. This raises the possibility that chronic high-dose zinc adversely affects prostate health. ${ }^{27}$

\section{Selenium}

Selenium toxicity can occur with acute or chronic high-dose ingestion. ${ }^{6}$ Early indicators of excess intake are 'garlic breath' and a metallic taste in the mouth. Signs of chronic high selenium intake or 'selenosis' are hair and nail loss or brittleness, lesions of the skin and nervous system, nausea, diarrhoea, skin rashes, mottled teeth, fatigue and mood irritability. Oral selenium products with a daily dose of 300 micrograms or more are regulated as Schedule 4 medicines because of their potential toxicity."

\section{Iron salts}

Adverse effects of oral iron supplements are dose related, so a key predictor of harm is assessing how much elemental iron is being taken. Some commercial iron supplements only contain tiny doses, that is 10-20 mg iron per unit, which reduces the risk of adverse effects but also the chance of benefit. Typical adverse effects of therapeutic iron doses, such as 100-200 mg/day include abdominal pain, nausea, vomiting, constipation, diarrhoea and black discolouration of faeces. Black discolouration of teeth is associated with liquid iron preparations.

\section{Folic acid}

Folic acid is well tolerated in fortified foods and supplemental doses used for medical indications up to $1 \mathrm{mg}$ daily. ${ }^{6}$ Doses from $5-15 \mathrm{mg} /$ day have been associated with a range of gastrointestinal adverse effects including abdominal cramps, diarrhoea, nausea, flatulence and a bitter taste in the mouth. ${ }^{6}$ Due to its antagonistic effects, folic acid reduces the adverse effects of methotrexate used in management of rheumatoid arthritis. However, it may decrease the efficacy of methotrexate in the treatment of acute lymphoblastic leukemia ${ }^{28}$ and psoriasis. ${ }^{29}$ Excess folate or folic acid may mask vitamin $\mathrm{B}_{12}$ deficiency. ${ }^{30}$

\section{Conclusion}

Dietary supplements have a range of potential risks and few benefits. Consumers should be aware that there is no case for vitamin or other supplements in normal healthy people, who are not pregnant or breastfeeding and are consuming a healthy diet. ${ }^{31}$ In order to make informed decisions about dietary supplement use, consumers require information on both their benefits and harms. As the risks of dietary supplements are not well known, manufacturers should be required to make this information more readily available. Health professionals and consumers should report adverse events associated with dietary supplements to the TGA. $<$

Conflicts of interest: none declared

\section{REFERENCES}

1. United States Food and Drug Administration. FDA 101: Dietary supplements. 2015 Jul 15. https://www.fda.gov/ consumers/consumer-updates/fda-101-dietary-supplements [cited $2021 \mathrm{Jul} 1]$

2. Complementary Medicines Australia. Australia's complementary medicines industry audit and trends 2020 Canberra: CMA; 2020. http://www.cmaustralia.org.au/page1859595 [cited $2021 \mathrm{Jul} 1]$
3. Steel A, Mclntyre E, Harnett J, Foley H, Adams J, Sibbritt D, et al. Complementary medicine use in the Australian population: Results of a nationally-representative crosssectional survey. Sci Rep 2018;8:17325. https://doi.org/ 10.1038/s41598-018-35508-y

4. MacLennan $\mathrm{AH}$. The four harms of harmless therapies. Climacteric 1999;2:73-4. https://doi.org/10.3109/ 13697139909025568 
5. Olson JM, Ameer MA, Goyal A. Vitamin A toxicity. [Updated 2021 Feb 11]. In: StatPearls [Internet]. Treasure Island (FL): StatPearls Publishing. https://www.ncbi.nlm.nih.gov/books/ NBK532916 [cited 2021 Jul 1]

6. Natural Medicines [database]. Somerville (MA): Therapeutic Research Center; 2021. https://naturalmedicines. therapeuticresearch.com [cited $2021 \mathrm{Jul} 1]$

7. Bastos Maia S, Rolland Souza AS, Costa Caminha MF, Lins da Silva S, Callou Cruz RS, Carvalho Dos Santos C, et al. Vitamin A and pregnancy: a narrative review. Nutrients 2019;11:681. https://doi.org/10.3390/nu11030681

8. Guyton JR, Bays HE. Safety considerations with niacin therapy. Am J Cardiol 2007;99(6A):S22-S31. https://doi.org/ 10.1016/j.amjcard.2006.11.018

9. Domanico D, Verboschi F, Altimari S, Zompatori L, Vingolo EM. Ocular effects of niacin: a review of the literature. Med Hypothesis Discov Innov Ophthalmol 2015;4:64-71.

10. Fraunfelder FW, Fraunfelder FT, Illingworth DR Adverse ocular effects associated with niacin therapy. Br J Ophthalmol 1995;79:54-6. https://doi.org/10.1136/ bjo.79.1.54

11. Poisons Standard June 2021. https://www.legislation.gov.au/ Details/F2021L00650 [cited $2021 \mathrm{Jul} 1$ ]

12. Thomas LD, Elinder CG, Tiselius HG, Wolk A, Åkesson A. Ascorbic acid supplements and kidney stone incidence among men: a prospective study. JAMA Intern Med 2013;173:386-8. https://doi.org/10.1001/jamainternmed.2013.2296

13. Auer BL, Auer D, Rodgers AL. Relative hyperoxaluria, crystalluria and haematuria after megadose ingestion of vitamin C. Eur J Clin Invest 1998;28:695-700. https://doi.org/ 10.1046/j.1365-2362.1998.00349.x

14. Jiang K, Tang K, Liu H, Xu H, Ye Z, Chen Z. Ascorbic acid supplements and kidney stones incidence among men and women: a systematic review and meta-analysis. Urol J 2019;16:115-20. https://doi.org/10.22037/uj.v0i0.4275

15. Heaney ML, Gardner JR, Karasavvas N, Golde DW, Scheinberg DA, Smith EA, et al. Vitamin C antagonizes the cytotoxic effects of antineoplastic drugs. Cancer Res 2008;68:8031-8. https://doi.org/10.1158/0008-5472.CAN-08-1490

16. Taylor PN, Davies JS. A review of the growing risk of vitamin D toxicity from inappropriate practice. Br J Clin Pharmacol 2018;84:1121-7. https://doi.org/10.1111/ bcp. 13573

17. Sullivan MG. Large, intermittent vitamin D doses may increase fracture, fall risk in elderly. Clinical Endocronology News 2017 Mar 03. www.mdedge.com/endocrinology/ article/132688/geriatrics/large-intermittent-vitamin-ddoses-may-increase-fracture?sso=true [cited $2021 \mathrm{Jul} 1$ ]

18. Sanders KM, Stuart AL, Williamson EJ, Simpson JA, Kotowicz MA, Young D, et al. Annual high-dose oral vitamin $D$ and falls and fractures in older women: a randomized controlled trial. JAMA 2010;303:1815-22. https://doi.org/10.1001/jama.2010.594
19. Burt LA, Billington EO, Rose MS, Kremer R, Hanley DA Boyd SK. Adverse Effects of high-dose vitamin D supplementation on volumetric bone density are greater in females than males. J Bone Miner Res 2020;35:2404-14. https://doi.org/10.1002/jbmr.4152

20. National Institutes of Health. Office of Dietary Supplements. Vitamin E fact sheet for health professionals. Last updated 2021 Mar 26. https://ods.od.nih.gov/factsheets/VitaminEHealthProfessional/\#h7 [cited 2021 Jul 1]

21. Bjelakovic G, Nikolova D, Gluud LL, Simonetti RG, Gluud C. Mortality in randomized trials of antioxidant supplements for primary and secondary prevention: systematic review and meta-analysis. JAMA 2007;297:842-57. https://doi.org/ 10.1001/jama.297.8.842

22. National Institutes of Health. Office of Dietary Supplements Calcium fact sheet for health professionals. Last updated 2021 Mar 29. https://ods.od.nih.gov/factsheets/CalciumHealthProfessional/\#h8 [cited 2021 Jul 1]

23. Drugdex. IBM Micromedex subscription database. Accessed via Clinicians Knowledge Network (QId Health). IBM Corporation 2020.

24. National Institutes of Health. Office of Dietary Supplements Magnesium fact sheet for health professionals. Last updated 2021 Mar 29. https://ods.od.nih.gov/factsheets/MagnesiumHealthProfessional/\#h8 [cited 2021 Jul 1]

25. Barbagallo M, Belvedere M, Dominguez LJ. Magnesium homeostasis and aging. Magnes Res 2009;22:235-46. https://doi.org/10.1684/mrh.2009.0187

26. National Institutes of Health. Office of Dietary Supplements. Zinc fact sheet for health professionals. Last updated 2020 Jul 15. https://ods.od.nih.gov/factsheets/ZincHealthProfessional/\#h8 [cited 2021 Jul 1]

27. Johnson AR, Munoz A, Gottlieb JL, Jarrard DF. High dose zinc increases hospital admissions due to genitourinary complications. J Urol 2007;177:639-43. https://doi.org/ 10.1016/j.juro.2006.09.047

28. Schrøder H, Clausen N, Ostergård E, Pressler T. Folic acid supplements in vitamin tablets: a determinant of hematologica drug tolerance in maintenance therapy of childhood acute lymphoblastic leukemia. Pediatr Hematol Oncol 1986;3:241-7. https://doi.org/10.3109/08880018609031223

29. Chládek J, Simková M, Vanecková J, Hroch M, Chládkova J, Martínková J, et al. The effect of folic acid supplementation on the pharmacokinetics and pharmacodynamics of oral methotrexate during the remission-induction period of treatment for moderate-to-severe plaque psoriasis. Eur J Clin Pharmacol 2008;64:347-55. https://doi.org/ 10.1007/s00228-007-0442-x

30. Cuskelly GJ, Mooney KM, Young IS. Folate and vitamin B12: friendly or enemy nutrients for the elderly. Proc Nutr Soc 2007;66:548-58. https://doi.org/10.1017/ S0029665107005873

31. Kennedy M. The vitamin epidemic: what is the evidence for harm or value? Intern Med J 2018;48:901-7. https://doi.org/ 10.1111/imj.13976 